\title{
Development of A Carbonization-in-Nitrogen Method for Measuring the Fiber Content of Carbon Fiber Reinforced Thermoset Composites
}

\author{
Qiushi Wang $^{a}$, Haibin Ning ${ }^{a^{*}}$, Uday Vaidya ${ }^{a}$, Selvum Pillay ${ }^{a}$ and Leigh Hudson ${ }^{b}$ \\ ${ }^{a}$ Department of Materials Science and Engineering \\ Materials Processing and Applications Development (MPAD) Center \\ University of Alabama at Birmingham \\ Birmingham, AL, 35294 \\ ${ }^{\mathrm{b}}$ Toray Carbon Fibers America, Decatur, AL 35601
}

\begin{abstract}
Carbon fiber reinforced thermoset composites such as carbon fiber epoxy composites are widely used in aircraft and aerospace, and are being increasingly used in automotive applications because of their lightweight characteristics, high specific strength, and stiffness. The carbon fiber content in the composite plays a critical role in enhancing structural performance. The carbon fibers contribute to the strength and stiffness; therefore, the mechanical properties of the composite are greatly influenced by the carbon fiber content. Measurement of carbon fiber content is essential for product quality control and process optimization. In this work, a novel carbonization-in-nitrogen method is developed to characterize the fiber content in carbon fiber thermoset composites. A carbon fiber composite sample is carbonized in a nitrogen environment at elevated temperatures, alongside a neat resin sample. The carbon fibers are protected from oxidization while the resin (the neat resin and the resin matrix in the composite sample) is carbonized under nitrogen environment. The neat resin sample is used to calibrate the resin carbonization rate and calculate the amount of the resin matrix in the composite sample. The new method has been validated on several thermoset resin systems, and found to yield accurate estimation of fiber content in carbon fiber thermoset composites.
\end{abstract}

Keywords: A. Carbon fiber; A. Thermosetting resin; D. Thermal Analysis; E: Lay up

* Corresponding author, Tel.: 205-996-7390; fax: 205-934-8485. Email: ning@uab.edu 


\section{Introduction}

Carbon fiber reinforced thermoset composites have been widely used in many high-performance applications because of their widely described advantages, especially high specific strength, stiffness and stiffness-to-weight ratios, and many other advantages [1-4]. It is known that the carbon fiber content, as one of the most important parameters, determines the mechanical and other properties of carbon fiber composites. Smith et al (2007), Chen et al (1999) and Simon (1987) et al have studied the effect of fiber content on resulting properties of composite materials [5-7]. Carbon fibers act as the primary reinforcement to provide strength and stiffness for fiber reinforced composites.

Traditionally, standard methods established by ASTM D3171-Standard Test Methods for Constituent Content of Composite Materials are applied for determining fiber content in carbon fiber composites [8]. These methods require that the resin matrix be completely removed from a carbon fiber composite either by acid digestion or burn-off in air and only the carbon fibers remain in the residue. Despite widespread use, the acid digestion and burn-off-in-air methods are not without limitations. The acid digestion method has been restricted to certain resin systems, such as polypropylene and epoxy, which could be dissolved completely in acids. Highly hazardous acids such as hydrochloric and sulfuric acids used in the acid digestion method could pose potential hazards to the operator, as well as the environment. In addition to the excessive time required for acid digestion, there are several semi-crystalline resins (e.g. polyimide) that cannot be dissolved in solvents (e.g. hydrochloric acids) [9]. The burn-off-in-air method is only applicable for resins that are easy to degrade at elevated temperatures. High temperature resins, such as epoxy (decomposition temperature $>400^{\circ} \mathrm{C}$ ) typically used in aircraft and automobile applications, will only totally degrade in air at temperatures that will also cause the carbon fibers to oxidize [10]. In addition, airborne carbon particles from matrix burn-off in air pose potential hazards to the operator and the environment.

Another method used for measuring carbon fiber content is Thermogravimetric Analysis (TGA), as reported by Polis [11]. In this method, a sample weighing less than 0.1 gram is used. This small sample size is not sufficiently representative of carbon fiber composite structures. The TGA method has not been widely adopted because of low confidence level which is derived from using small sample size ( 0.1 gram) to represent large composite structures.

Optical microscopy is another method which has been reported by Purslow et al (1984) and Cohen et al (2001) [12-13]. The fiber content is measured through optical image analysis, with the image obtained from a polished composite sample. The accuracy of this method is highly dependent on sample preparation, number of cross-sections being examined, and image filtering. In addition, a sufficient number of cross-sectional surfaces should be examined in order to obtain a fiber content representative of 


\section{Experiment}

\subsection{Procedure Description}

A carbonization-in-nitrogen method is developed to characterize carbon fiber reinforced thermoset composites. A carbon fiber reinforced thermoset composite is carbonized in a nitrogen-purging tube furnace along with a reference neat (unreinforced) resin. The reference neat resin is the same as that used in the carbon fiber reinforced composite. However, it may be difficult to procure the neat resin sample in some cases, which could be the drawback of this method. During carbonization in nitrogen, the resin matrix in the carbon fiber composite and the reference neat resin are carbonized under high temperature $\left(400-600^{\circ} \mathrm{C}\right)$ and inert atmosphere. The inert atmosphere is required to avoid oxidation of the carbon fibers. The products of the carbonization of the neat resin and the resin from the composite include both gaseous fumes that are vented and carbonized residue that remains in the furnace. The carbonized residue from the reference neat resin provides the percentage of carbonization of the resin. This residue information can be used to calculate the amount of resin matrix in the composite. Figure 1 illustrates the procedure. Carbonization rate $(\mathrm{CR})$ of the neat resin can be estimated from the neat resin sample $\left(m_{i}\right)$ and its residue $\left(m_{c r}-m_{c}\right)$ in accordance with Eq. (1):

$$
C R=\left(m_{c r}-m_{c}\right) / m_{i}
$$

where $\mathrm{CR}$ - carbonization rate of the reference neat resin, $\mathrm{m}_{\mathrm{cr}}$ - residue mass from the reference neat resin sample in its crucible, $\mathrm{m}_{\mathrm{c}}$ - the crucible mass and $\mathrm{m}_{\mathrm{i}}$ - reference neat resin sample mass.

The carbon fiber content (weight fraction), $W_{f}$, in the composite sample could be calculated in accordance with Eq. (2) that is developed for the first time:

$$
\left.W_{f}=\left(\left(M_{i}-M_{m}\right) / M_{i}\right) \times 100=\left(\left(M_{c r}-M_{c}\right)-M_{i} \times C R\right) /\left(M_{i} \times(1-C R)\right)\right) \times 100
$$

where $\mathrm{W}_{\mathrm{f}}$ - carbon fiber content, $\mathrm{M}_{\mathrm{i}}$ - carbon composite sample mass, $\mathrm{M}_{\mathrm{m}}$ - the mass of the resin matrix in the composite sample, $\mathrm{M}_{\mathrm{cr}}$ - the mass of the composite residue in its crucible, and $\mathrm{M}_{\mathrm{c}}$ - the crucible mass..

\subsection{Materials and Equipment}

In order to verify the procedure described above, experiments were conducted with two typical carbon fiber reinforced thermoset systems - carbon fiber/epoxy and carbon fiber/vinyl ester because they are commonly used resin systems. Samples with known fiber contents were manufactured using hand lay-up process. In addition, some composite samples were tested in Toray Carbon Fibers America, Decatur, AL 

caused by the operator and equipment. The known carbon fiber contents of these samples were used to compare to the results obtained from the developed carbonization procedure. The materials and equipment, the carbonization procedure, the manufacture and characterization of the composites, and the experimental uncertainties are introduced in the following sections.

The epoxy resin used for all samples was West System Epoxy 105. The curing agent used was West System 206. The resin/curing agent mass ratio was 100/20.5. The vinyl ester resin used was Derakane TM 411-350, manufactured from Ashland. The curing agent is a mixer of catalyst Trigonox 239, accelerator of Cobalt and inhibitor of Acetyl Acetone. The resin/curing agent mass ratio was 100/1.95. The carbon fibers fabric sheets were Pyrofil in 12k tows with standard sizing, manufactured from Mitsubishi Rayon Japan. The furnace used was Lindberg Blue M 55367. The sample mass was measured on a Mettler Delta range AT 261 balance. Thermogravimetric analyses were done on a Dupont TGA 2950 analyzer.

\subsection{Determination of Carbonization Temperature}

Thermo-gravimetric analysis (TGA) was conducted on constituent resin and carbon fibers to determine an optimized temperature to carbonize the samples in nitrogen. Figure 2 and 3 illustrate the results for the matrix epoxy resin and vinyl ester used in this study, respectively. The heating rate was $20^{\circ} \mathrm{C} / \mathrm{min}$ and each sample was held at $600^{\circ} \mathrm{C}$ for $120 \mathrm{~min}$. The epoxy and vinyl ester resins have approximately $15 \%$ mass loss at around $350^{\circ} \mathrm{C}$. The nearly flat line on the TGA curves indicates that there is no noticeable mass change after 100 -minute dwell at $600^{\circ} \mathrm{C}$. The carbonized residue percentage for epoxy and vinyl ester is $5.0 \%$ and $4.1 \%$, respectively. Figure 4 shows an isothermal curve for carbon fiber at $600{ }^{\circ} \mathrm{C}$, and a mass loss of around 1.2\% mass fraction occurs after 60 minutes. The mass loss is attributed to the sizing degradation and possible moisture. Based on the TGA results, the temperature for the carbonization in nitrogen is determined to range from 400 to $600^{\circ} \mathrm{C}$. In this temperature range, carbon fiber shows no degradation while the resin shows relatively stable carbonization rate.

\subsection{Sample Manufacturing}

A number of composite samples with different carbon fiber contents were prepared for testing at the UAB Materials Processing and Applications Development (MPAD) Center. The samples involved three different compositions $(20-30 \%, 40-50 \%, 60-70 \%)$ based on the number of carbon fabric layers. The composites were processed by hand lay-up. Carbon fiber sheet was cut to $40 \mathrm{~mm}$ x $40 \mathrm{~mm}$ and weighed to a predetermined mixture depending on the desired composition. During the hand lay-up process, the release agent was sprayed on the work surface to form a release layer between the sample and the work surface. A carbon fiber sheet of known weight was placed on the top of a glass table and then thermoset resin was used to wet out the carbon fiber sheet. A vacuum was applied to create even pressure, and draw 

samples were cured at room temperature and used for the following carbonization procedure. Figure 5 shows the samples and the hand lay-up process used to prepare the samples.

\subsection{Carbonization in Nitrogen}

The composite samples and the reference neat resin samples were placed in a nitrogen-purging tube furnace as shown in Figure 6 after drying. The samples were heated to at least $400^{\circ} \mathrm{C}$ and held at that temperature for 60 minutes. The resin in the composite samples and reference neat resin samples was carbonized simultaneously under identical thermal conditions. The sample residue was weighed after being cooled down to room temperature. Some samples were processed and carbonized at Toray Carbon Fibers America, Decatur, Alabama to prove that the developed method is applicable in different labs. Figure 7(a) shows the residue from the composite sample after carbonization. Figure 7(b) shows the residue from the carbonized reference neat resin sample, which is used to calibrate the percentage of matrix residue from the carbon fiber composite sample shown in Figure 7(a).

\section{Results and Discussion}

\subsection{Carbon Fiber Vinyl Ester Composite}

Table 1 illustrates a comparison between the nominal fiber content and the measured fiber contents from carbonization tests for a batch of carbon/vinyl ester samples. The nominal fiber content was obtained by using the mass of dry carbon fiber over the mass of the cured composite sample during the sample preparation process. The carbon fiber content from the carbonization test was calculated from Equation 2. The deviation of the carbon fiber content between the nominal and carbonization-in-nitrogen method is minimal when compared to the nominal fiber content as shown in Figure 8. The small deviation indicates the carbonization-in-nitrogen method could be used to measure the carbon fiber content in the carbon/vinyl ester samples. The small deviation could be attributed to possible moisture absorption and the sizing of the carbon fiber.

\subsection{Carbon Fiber Epoxy Composite}

Table 2 lists the measured fiber contents for a set of carbon fiber reinforced epoxy samples used in validating the developed method. The deviation between the actual nominal fiber content and the fiber content from developed carbonization-in-nitrogen method is minimal as illustrated in Table 2. It indicates the developed method could be used to calculate the carbon fiber weight fraction in the epoxy resin composites. Figure 9 shows the comparison between the calculated results with the nominal results for carbon/epoxy samples for a batch of 5 samples. The small deviations illustrate that the carbonization-innitrogen method could be applied to the epoxy system. 
Figure 10 summarizes different batches of samples carbonized at different times, with different carbon fiber contents, at different testing facilities, at different temperatures, and by different operators. The results in Figure 10 show that the calculated carbon fiber contents in epoxy and vinyl ester are similar to the actual nominal fiber contents with no more than $2 \mathrm{wt} \%$ deviation. Considering the fiber content is normally over $40 \mathrm{wt} \%$, the deviation is minimal. Sizing degradation is not considered in the calculation because of its negligible effect on the results. The low deviation indicates that this method is suitable in determining the fiber content in practice as a generalized method.

\section{Conclusion}

A new carbonization-in-nitrogen method has been developed to measure the fiber content in carbon fiber thermoset matrix composites. A reference neat resin sample was carbonized with a carbon fiber thermoset composite sample under nitrogen environment at a temperature ranging from $400^{\circ} \mathrm{C}$ to $600^{\circ} \mathrm{C}$. The carbon fibers were protected from oxidization while the resin was carbonized. The carbonization rate of the reference neat resin sample was used to calculate the amount of the resin matrix in the composite sample. The results from the carbonization-in-nitrogen method demonstrate that the method can be used as a generalized way to determine fiber content in carbon fiber reinforced thermoset composites effectively and accurately.

\section{Acknowledgements}

The authors would like to acknowledge Department of Energy (DOE) Graduate Automotive Technology Education (GATE) program for funding this work.

\section{References}

[1] L.A. Dobrzaski, A. Pusz, and A.J. Nowak, Aramid-silicon laminated material with special properties-new perspective of its usage, Journal of Achievements in Materials and Manufacturing Engineering, 28/1 (2008) 7-14.

[2] W. Hufenbach, L.A. Dobrzaski, M. Gude, J. Konieczny, and A.Czulak, Optimization of the rivet joints of the CFRP composite material and aluminum alloy, Journal of Achievements in Materials and Manufacturing Engineering, 20 (2007) 119-122.

[3] K. Jamroziak, and M. Bocian, Identification of composite materials at high speed deformation with the use of degenerated model, Journal of Achievements in Materials and Manufacturing Engineering, 28/2 (2008) 171-174.

[4] S.B. Heru, J. Komotori, M. Shimizu, and Y. Miyano, Effects of the fiber content on the longitudinal tensile fracture behavior of uni-directional carbon/epoxy composites, Journal of Materials Processing Technology, 67 (1997) 89-93. 
[5] Okoli, and G.F. Smith, Failure modes of fiber reinforced composites: The effect of strain rate and fiber content, Journal of Materials Science, 33 (1998) 5415-5422.

[6] J.H. Chen, E. Schulz, J. Bohse, G. Hinrichsen, Effect of fiber content on the interlaminar fracture toughness of unidirectional glass-fiber/polyamide composite, Composites A, 30 (1999) 747-755.

[7] S. Simon and L. Strunk, Fibre volume of resin matrix composites by density measurement, Int. SAMPE Symp. Exihib. 32 (1987) 116-22.

[8] ASTM D3171 Test method for constituent content of composite materials. ASTM International, West Conchohocken, 2012

[9] Dupont Kapton Polyimide Film General Specifications, Bulletin GS-96-7, http://www.dupont.com/kapton/general/H-38479-4.pdf , accessed in August 2014.

[10] C.L. Chiang and R.C. Chang. Thermal stability and degradation kinetics of novel organic/inorganic epoxy hybrid containing nitrogen/slicon/phosphorus by sol-gel method, Thermochimica Acta, 453(2007) 97-104.

[11] L. P. Daniel and M.F. Sovinski, Determination of fiber volume in carbon/cyannate ester composites using thermogravimetric analysis (TGA), NASA/TM-2006-214143.

[12] D. Purslow, On the optical assessment of the void content in composite materials, Composites, 15 (1984) 207-210.

[13] D. Cohen, S.C. Mantell, and L. Zhao. The effect of fiber volume fraction on filament wound composite pressure vessel strength, Composites, 32B (2001) 413-429. 


\section{Figures}

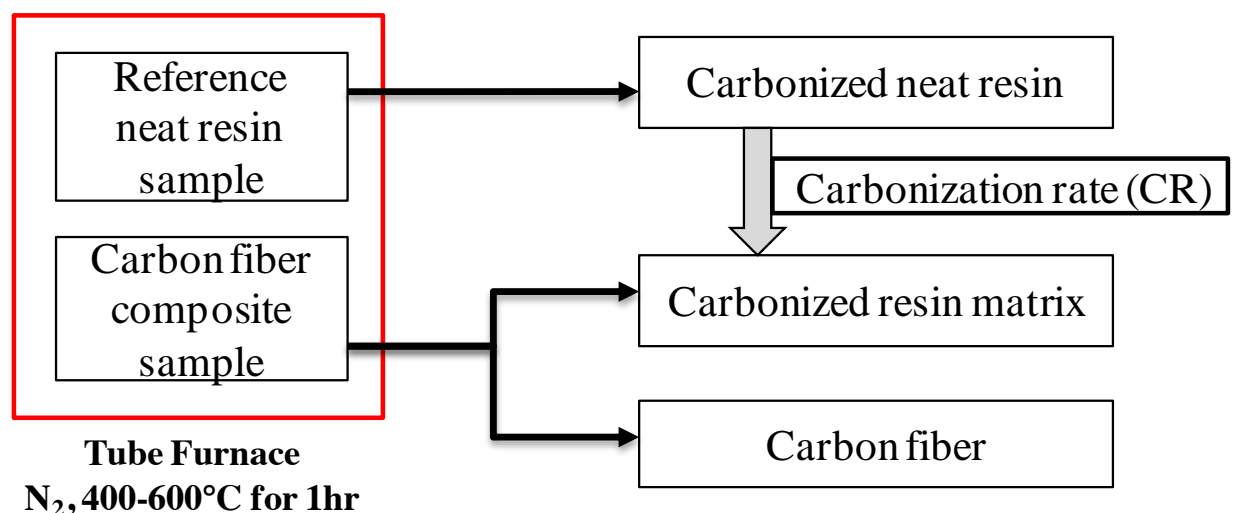

Figure 1. The carbonization-in-nitrogen flow chart. Note that the carbonization rate (CR) is used for calculating the amount of resin matrix in the composite sample.

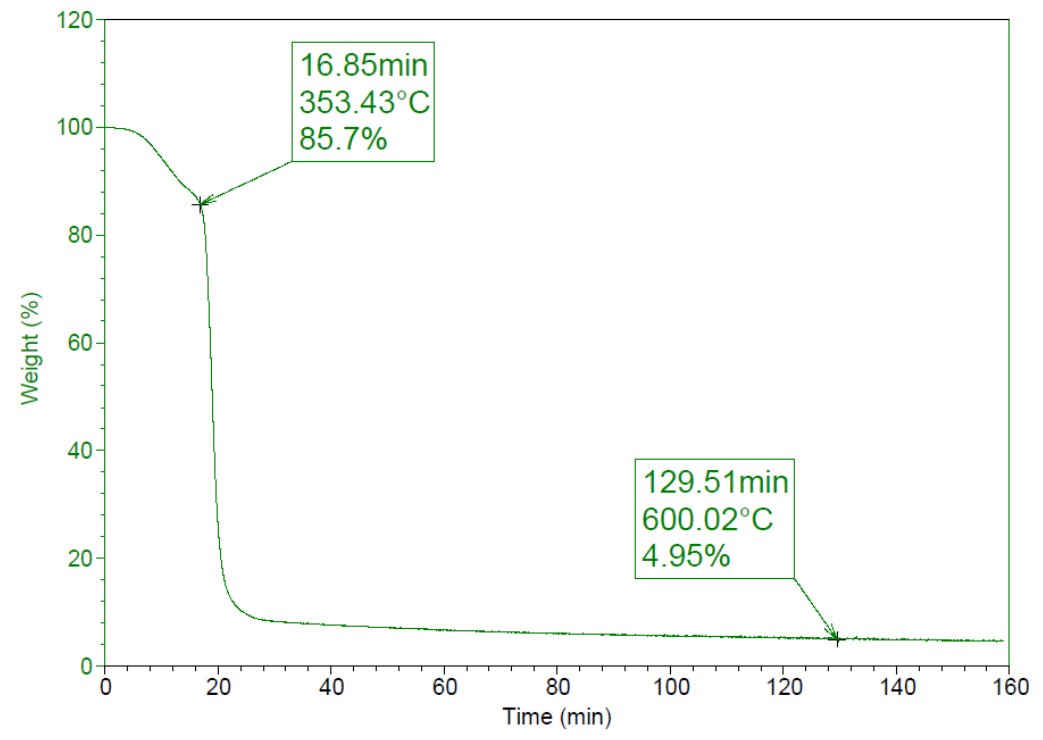

Figure 2. TGA plot of the mass fraction loss of epoxy resin at $600^{\circ} \mathrm{C}$. Note that the resin still has residue after 60 min in nitrogen. 


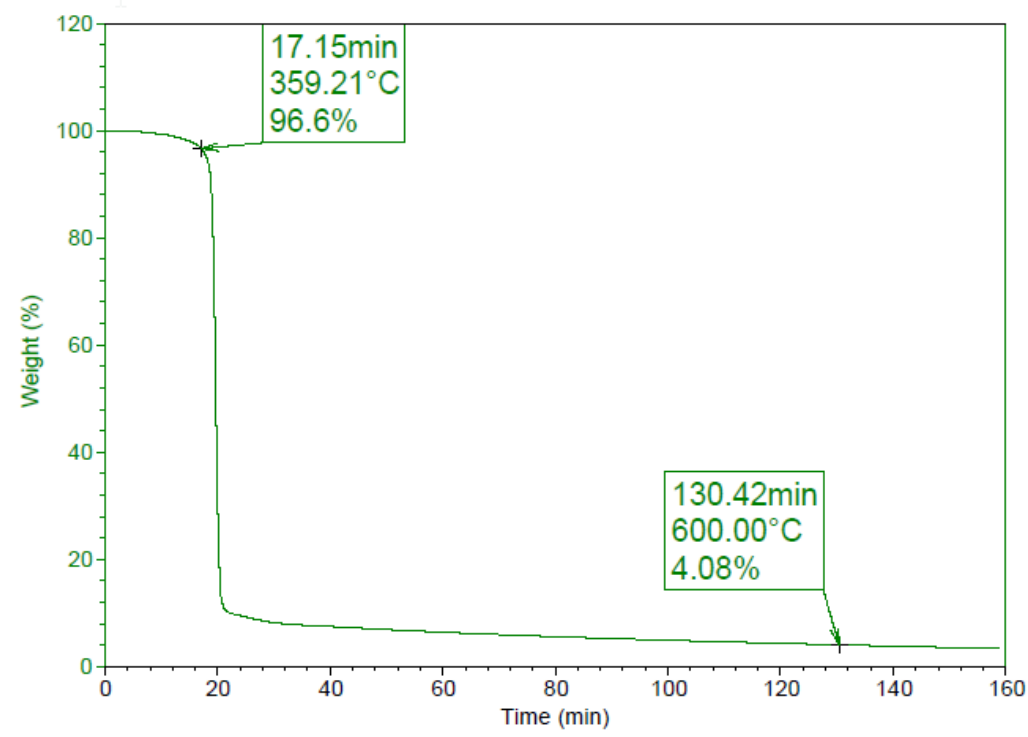

Figure 3. TGA plot of the mass fraction loss of vinyl ester resin at $600^{\circ} \mathrm{C}$. Note that the resin still has residue after $60 \mathrm{~min}$ in nitrogen.

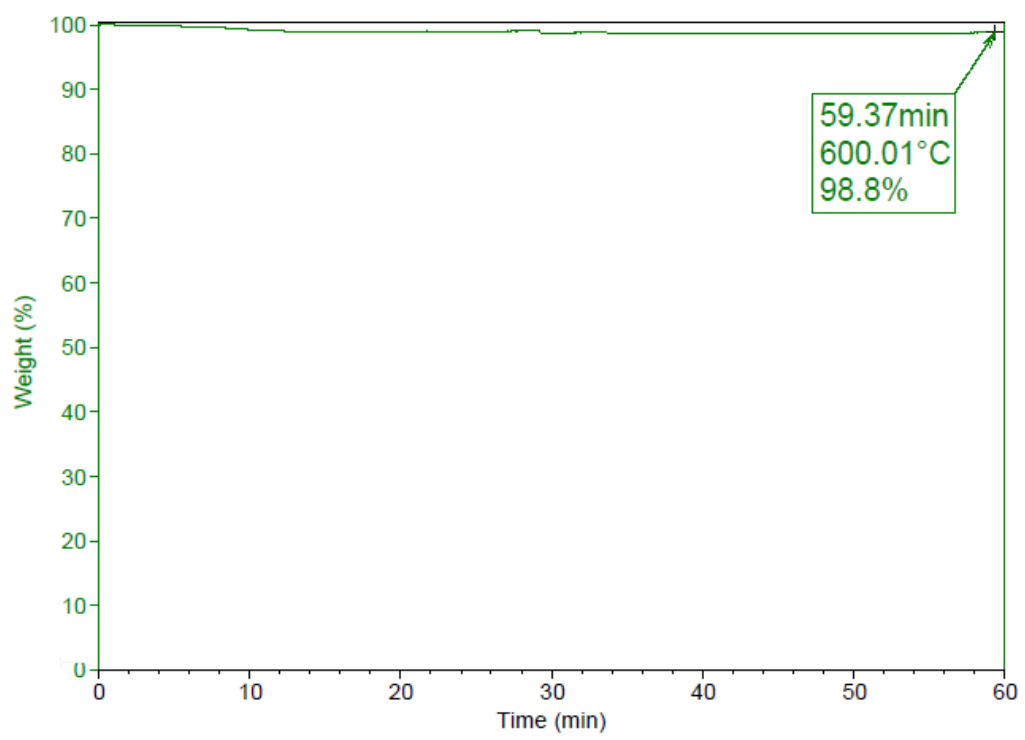

Figure 4. TGA plot of the mass fraction loss of carbon fiber at $600^{\circ} \mathrm{C}$ in nitrogen. 


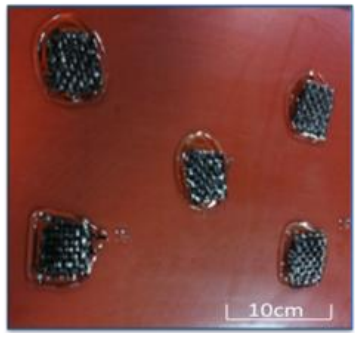

(a)

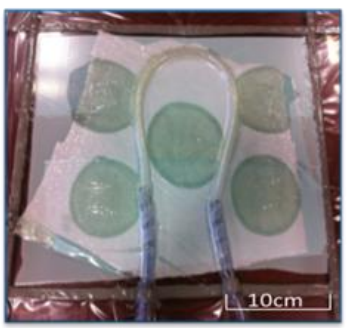

(b)

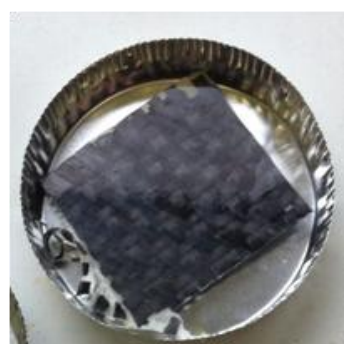

(c)

Figure 5. Hand lay-up method to prepare carbon fiber thermoset composite samples. (a) Carbon fiber wet out with resin; (b) vacuum applied to consolidate the individual samples; (c) A representative cured sample with known fiber content ready for carbonization-in-nitrogen testing.

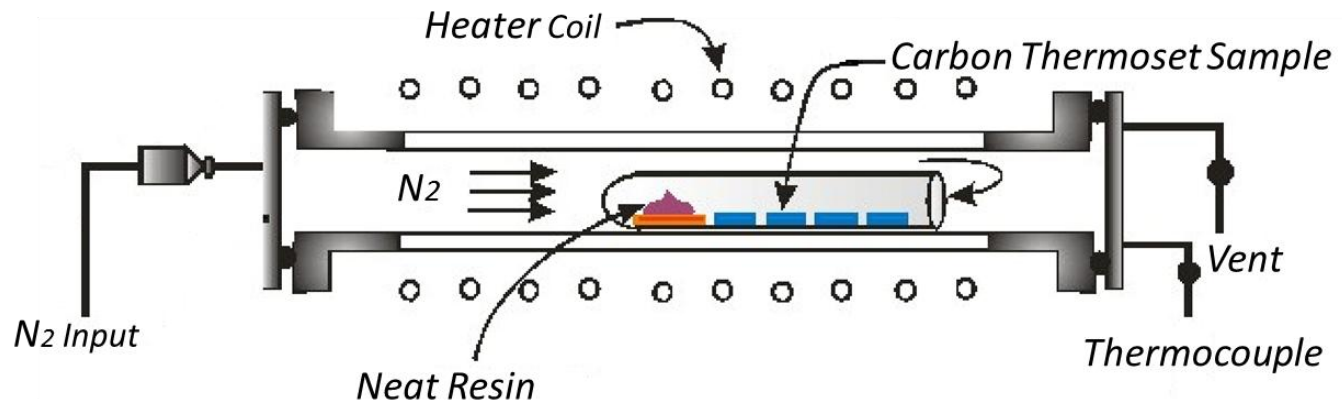

Figure 6. Tube furnace used for the carbonization method.

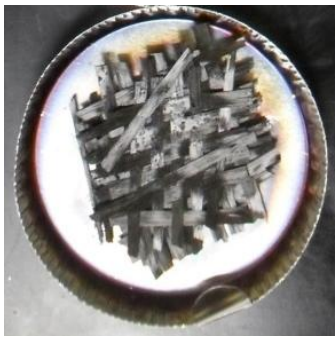

(a)

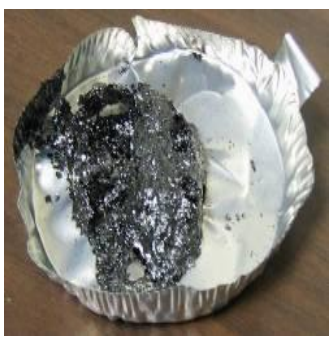

(b)

Figure 7. (a) Residue after carbonization-in-nitrogen for the sample shown in Figure 5(c); and (b) residue from reference neat resin after carbonization-in-nitrogen for calibration. 


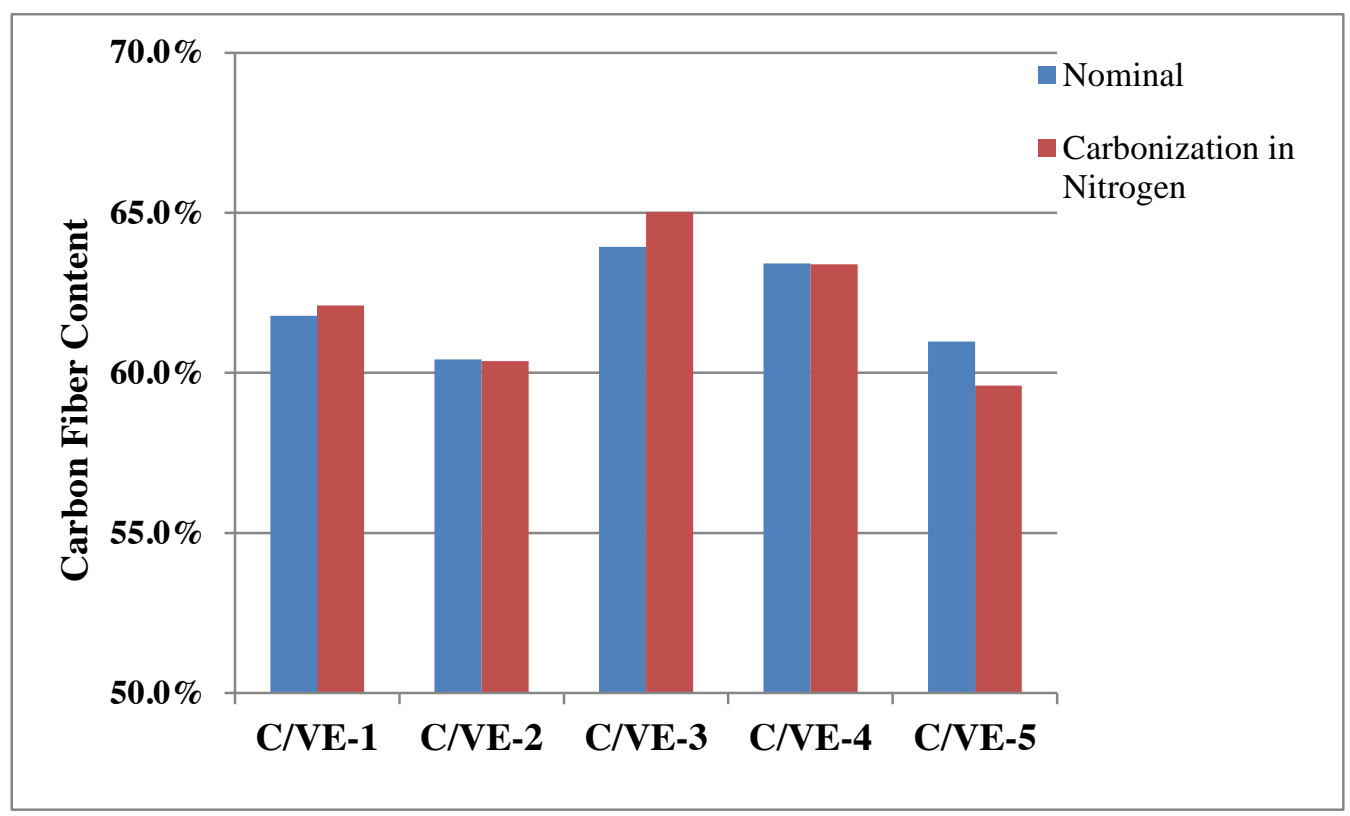

Figure 8. Comparison between fiber content from carbonization in nitrogen and nominal fiber content in a batch of five carbon vinyl ester samples.

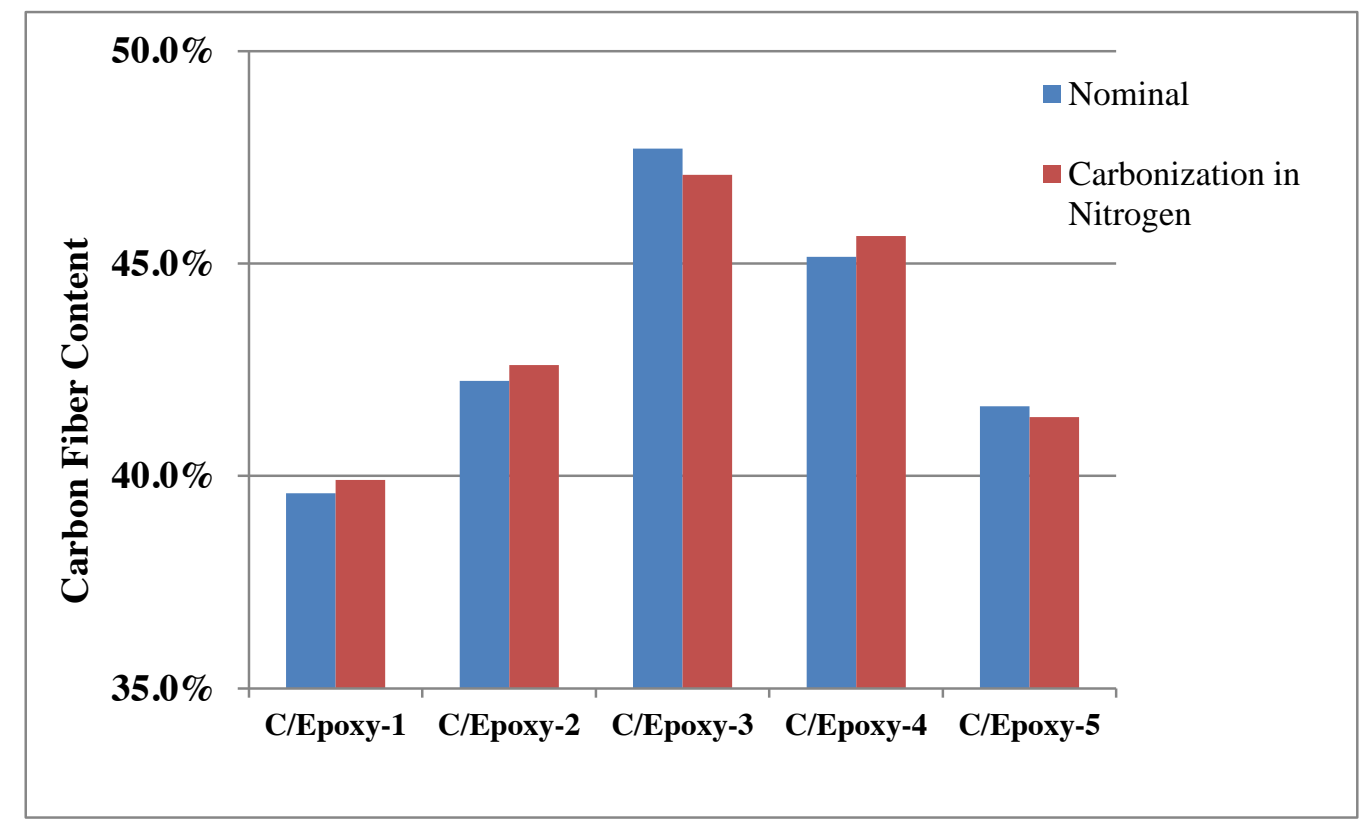

Figure 9. Comparison between fiber content from carbonization in nitrogen and nominal fiber content in a batch of five carbon epoxy samples. 


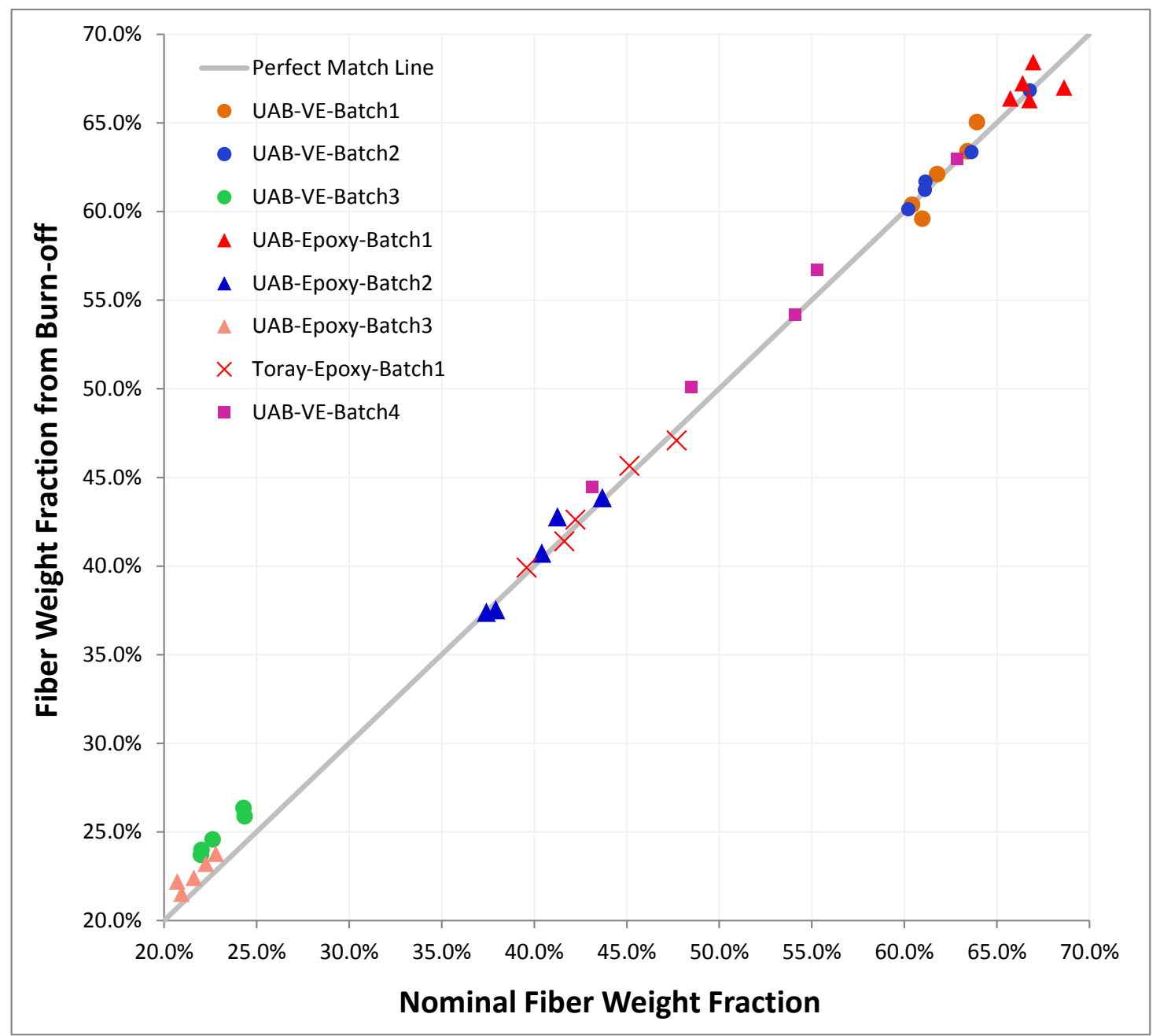

Figure 10. The comparison between the actual fiber content with the fiber content measured using the developed carbonization method. 


\section{Tables}

Table 1. The fiber content results for one batch of carbon vinyl ester samples.

\begin{tabular}{|c|c|c|c|c|c|c|}
\hline Sample & $\begin{array}{c}\text { Total mass } \\
\mathbf{( g )}\end{array}$ & $\begin{array}{c}\text { Carbon Fiber } \\
\text { mass (g) }\end{array}$ & $\begin{array}{c}\text { Residue } \\
\text { mass (g) }\end{array}$ & $\begin{array}{c}\text { Nominal Fiber } \\
\text { Content }\end{array}$ & $\begin{array}{l}\text { Fiber Content from } \\
\text { Carbonization in } \mathbf{N}_{\mathbf{2}}\end{array}$ & Deviation \\
\hline C/VE-1 & 3.593 & 2.22 & 2.404 & $61.8 \%$ & $62.1 \%$ & $\mathbf{0 . 3 \%}$ \\
\hline C/VE-2 & 3.707 & 2.24 & 2.424 & $60.4 \%$ & $60.4 \%$ & $\mathbf{- 0 . 1 \%}$ \\
\hline C/VE-3 & 3.363 & 2.15 & 2.336 & $63.9 \%$ & $65.0 \%$ & $\mathbf{1 . 1 \%}$ \\
\hline C/VE-4 & 2.996 & 1.90 & 2.038 & $63.4 \%$ & $63.4 \%$ & $\mathbf{0 . 0 \%}$ \\
\hline C/VE-5 & 3.378 & 2.06 & 2.186 & $61.0 \%$ & $59.6 \%$ & $\mathbf{- 1 . 4 \%}$ \\
\hline Neat VE & 2.890 & --- & 0.366 & -- & -- & -- \\
\hline
\end{tabular}

Table 2. The fiber content results for one batch of carbon epoxy samples.

\begin{tabular}{|c|c|c|c|c|c|c|}
\hline Sample & $\begin{array}{c}\text { Total Mass } \\
(\mathbf{g})\end{array}$ & $\begin{array}{c}\text { Carbon Fiber } \\
\text { Mass (g) }\end{array}$ & $\begin{array}{c}\text { Residue } \\
\text { Mass (g) }\end{array}$ & $\begin{array}{c}\text { Nominal Fiber } \\
\text { Content }\end{array}$ & $\begin{array}{l}\text { Fiber Content from } \\
\text { Carbonization in } \mathbf{N}_{\mathbf{2}}\end{array}$ & Deviation \\
\hline C/Epoxy-1 & 4.505 & 1.783 & 1.961 & $39.6 \%$ & $39.9 \%$ & $\mathbf{0 . 3 \%}$ \\
\hline C/Epoxy-2 & 4.095 & 1.730 & 1.887 & $42.2 \%$ & $42.6 \%$ & $\mathbf{0 . 4 \%}$ \\
\hline C/Epoxy-3 & 3.977 & 1.897 & 2.000 & $47.7 \%$ & $47.1 \%$ & $\mathbf{- 0 . 6 \%}$ \\
\hline C/Epoxy-4 & 3.998 & 1.806 & 1.956 & $45.2 \%$ & $45.6 \%$ & $\mathbf{0 . 5 \%}$ \\
\hline C/Epoxy-5 & 4.348 & 1.811 & 1.954 & $41.6 \%$ & $41.4 \%$ & $\mathbf{- 0 . 3 \%}$ \\
\hline Neat epoxy & 5.667 & -- & 0.343 & -- & -- & -- \\
\hline
\end{tabular}

